\section{Assessing most relevant factors to simulate current annual increments of beech forests in Italy}

\author{
Marta Chiesi ${ }^{(1)}$, Fabio Maselli ${ }^{(1)}$, Gherardo Chirici ${ }^{(2)}$, Piermaria Corona ${ }^{(3)}$, \\ Fabio Lombardi ${ }^{(2)}$, Roberto Tognetti ${ }^{(2-4)}$, Marco Marchetti ${ }^{(2)}$
}

Recent papers have demonstrated the applicability of a calibrated bio-geochemical model - BIOME-BGC - for estimating current annual increments (CAls) of Mediterranean forests. In this study, the above model is applied to assess the gross primary production (GPP) of nine beech forest sites in Italy using a previously produced data set of meteorological data over a ten-year period (19992008). The obtained GPP estimates are integrated with relevant autotrophic respiration and allocation to obtain forest net primary production (NPP) averages for the same forests. The simulations are performed assuming different levels of ecosystem disequilibrium, i.e., progressively taking into account the effects of specific site history in terms of woody biomass removal and stand aging. The NPP estimates, converted into CAls by means of specific coefficients, are validated through comparison with data derived from tree growth measurements. Results indicate that the modeling of quasi-equilibrium conditions tends to produce overestimated CAI values, particularly for not fully stocked, old stands. The inclusion of information on existing biomass leads to a partial improvement, while optimal results are obtained when information on ecosystem development phase is considered. The implications of using different NPP estimation methods are finally discussed in the perspective of assessing the forest carbon budget on a national basis.

Keywords: CAI, NPP, Dendrochronological Data, Volume, Stand Age, BIOME-BGC

\section{Introduction}

Forests cover about one third of water-free land areas (FAO 2010) and are important for timber production, recreational purposes, biodiversity conservation and erosion prevention. In addition, forests can act as carbon sink mitigating the consequences of climate changes (Coops et al. 1998). Given the increased importance of the above forest functions, the need for monitoring forest stocks not only on a local scale, as commonly done for commercial purposes, but also on a regional/global scale is currently felt by ecologists (e.g., Tupek et al. 2010).

More specifically, the spatio-temporal variations of forest carbon stocks and fluxes must be known in order to properly assess the land carbon balance on different spatial and temporal scales (Allen et al. 2010, Powell et al. 2010). Efficient monitoring and reporting systems capable of quantifying variation of forest yields are therefore needed (Corona 2010). Traditionally this objective has been fulfilled by the application of forest inventories, so as to obtain both basic forest attributes (e.g., basal area, stem volume, etc.) and current annual increment (CAI), defined as the mean woody biomass accumulated an-

(1) IBIMET-CNR, Via Madonna del Piano 10, I-50019 Sesto Fiorentino (FI - Italy); (2) Dipartimento di Bioscienze e Territorio (DIBT), University of Molise, Contrada Fonte Lappone, I-86090 Pesche (Italy); (3) Consiglio per la Ricerca e la Sperimentazione in Agricoltura, Forestry Research Centre (CRA-SEL), viale Santa Margherita 70, I-01100 Arezzo (Italy); (4) The EFI Project Centre on Mountain Forests (MOUNTFOR), Fondazione Edmund Mach, via Edmund Mach, I-38010 San Michele all'Adige (Italy)

@) Marta Chiesi (m.chiesi@ibimet.cnr.it)

Received: Jan 04, 2013 - Accepted: Nov 22, 2013

Citation: Chiesi M, Maselli F, Chirici G, Corona P, Lombardi F, Tognetti R, Marchetti M, 2014. Assessing most relevant factors to simulate current annual increments of beech forests in Italy. iForest 7: 115-122 [online 2013-12-31] URL: http://www.sisef.it/iforest/ contents/?id=ifor0943-007

Communicated by: Giorgio Matteucci nually over a certain number of years (usually from five to ten). Forest inventories, however, require very expensive and timeconsuming field surveys and cannot be carried out frequently (Tupek et al. 2010).

An interesting alternative is the application of advanced methodologies quantifying forest production variations based on the combined use of remotely sensed data and biogeochemical models. Maselli et al. (2009a) proposed an approach based on the biogeochemical model BIOME-BGC to simulate the CAI of forests in quasi-equilibrium with the climatic and edaphic conditions of each site. More specifically, calibrated versions of BIOME-BGC were applied to simulate photosynthesis, respiration and allocation processes for each forest type. In this way, most factors determining the spatio-temporal variation of CAI can be taken into account. Among these factors, the first to be considered is the composition in species, whose genetic and physiological characteristics strongly affect CAI variability (Assmann 1970). Moreover, knowledge of site conditions (i.e., the site index) is required, in that potential growth in each site and maximum tree development stems from the interaction between climate and soil. Other important factors are those related to biomass removal in each site, including the management practices applied (thinning and cutting operations), forest fires, diseases occurred, etc. Finally, the stand development stage must be taken into consideration, since forest production is strictly dependent on tree age (e.g., Gower et al. 1996, Smith \& Long 2001, Wang et al. 2011). In fact, it is well known that old forests reduce their growth rate because of varying allocation properties (e.g., constant gross primary production - GPP coupled with increasing respiration due to higher biomass), nutrient limitations, changes in hydraulic architecture, and decreased stand leaf area (Smith \& Long 2001). The inclusion of all the mentioned factors within the proposed CAI modeling strategy can be carried out at different levels of complexity, depending on available input data and spatial and temporal scales of model application. This is expected to impact the accuracy of the model output in a way that has not yet been fully assessed.

The current paper aims at investigating the applicability of the model BIOME-BGC to assess current annual increments (CAIs) of nine beech forest sites spread over the Italian peninsula. Conventional forest measurements and tree growth data were fully available for all the sites considered. Moreover, various types of ancillary and remote sensing data were considered in the analysis. Data modeling was applied to obtain CAI estimates using progressively increasing information on each forest ecosystem (i.e., site 


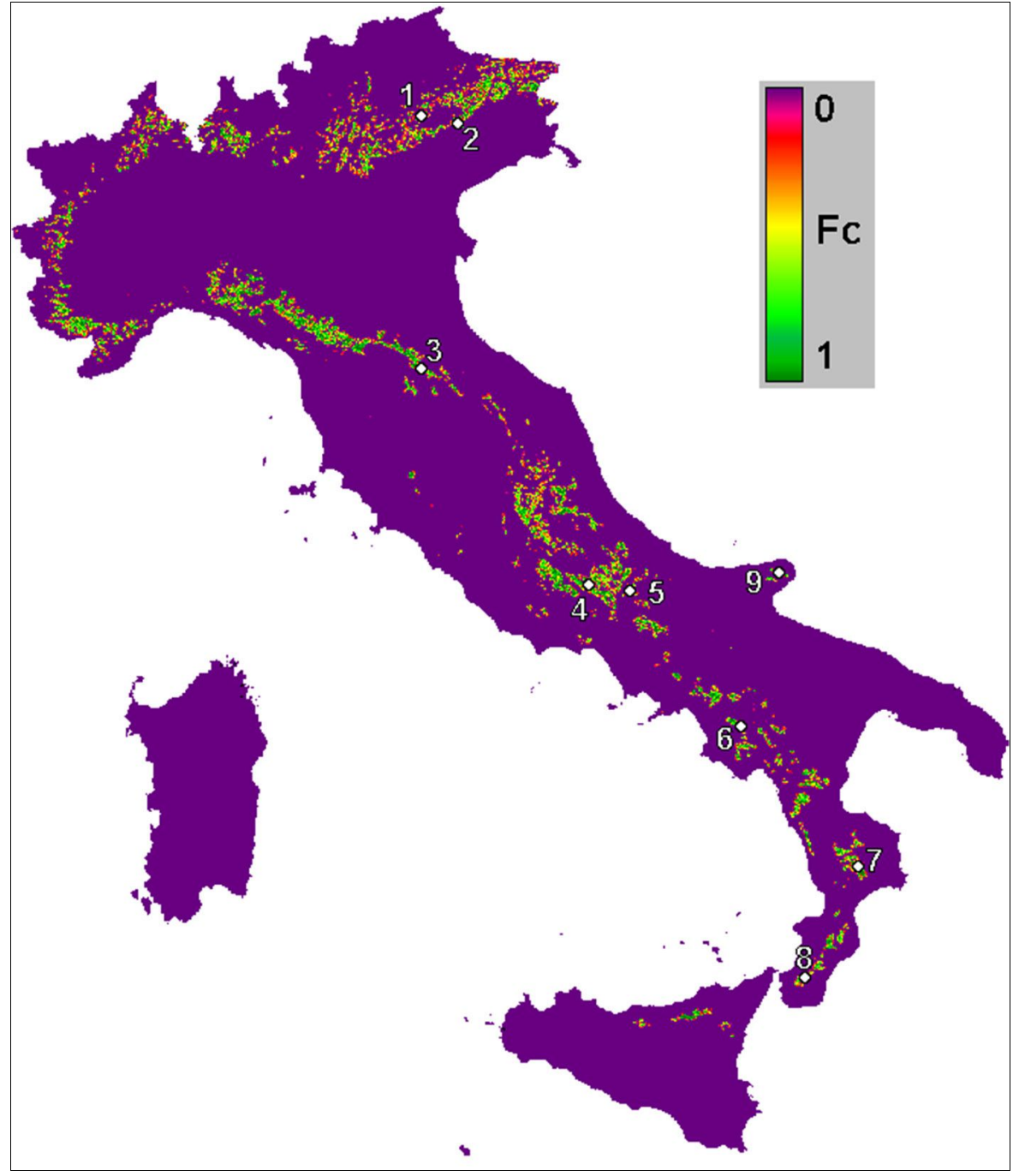

Fig. 1 - Fractional cover $(\mathrm{Fc})$ of beech forests in Italy derived from the CORINE Land Cover $2006\left(5^{\circ}-20^{\circ}\right.$ Long. E, 36-48 Lat. N). White circles indicate the location of the nine beech forest sites considered in this study (the IDs refer to the site names reported in Tab. 1).

condition, existing biomass and forest development phase). Finally, the accuracy of the CAI predictions obtained was tested by comparison to CAI measurements from tree growth data.

The paper is organized as follows. The main features of the selected forests are first described along with the ground and remote sensing data applied in the study. The modeling approach is then introduced, together

Tab. 1 - Main environmental characteristics of the beech forest sites studied. Meteorological data were derived from the downscaled E-OBS dataset (see text for more details).

\begin{tabular}{lccccc}
\hline Study site & $\begin{array}{c}\text { ID } \\
\text { point }\end{array}$ & $\begin{array}{c}\text { Geo-location } \\
(\text { Long. E, Lat. N) }\end{array}$ & $\begin{array}{c}\text { Altitude } \\
(\mathbf{m} \text { a.s.l.) }\end{array}$ & $\begin{array}{c}\text { Average } \\
\text { annual temp. } \\
\left({ }^{\circ} \mathbf{C}\right)\end{array}$ & $\begin{array}{c}\text { Average } \\
\text { annual rainfall } \\
(\mathbf{m m} / \mathbf{y})\end{array}$ \\
\hline Dolomiti Bellunesi & 1 & $11.91,46.12$ & 1100 & 8.75 & 768.6 \\
Pian del Cansiglio & 2 & $12.38,46.04$ & 1300 & 7.5 & 974.47 \\
Sasso Fratino & 3 & $11.79,43.84$ & 1550 & 9.61 & 1708.97 \\
Val Cervara & 4 & $13.73,41.83$ & 1780 & 7.97 & 694.03 \\
Monte di Mezzo & 5 & $14.21,41.75$ & 1100 & 11.19 & 613.48 \\
Corleto & 6 & $15.42,40.47$ & 1130 & 11.67 & 655.73 \\
Sila & 7 & $16.65,39.13$ & 1680 & 9.89 & 806.26 \\
Aspromonte & 8 & $15.94,38.17$ & 1560 & 12.29 & 660.63 \\
Gargano & 9 & $16.01,41.82$ & 775 & 14.2 & 509.03 \\
\hline
\end{tabular}

with the steps used for its application and validation against available increment data. Next, the results are described and commented, with particular reference to examining the main sources of uncertainty in the evaluation of CAI. The paper is concluded by a section which highlights the potential contribution of the approach for the assessment of forest carbon budget on a national scale.

\section{Study areas and data}

\section{Study areas}

Beech (Fagus sylvatica L.) is a deciduous species widely distributed within European temperate forests, growing in environments relatively little affected by wildfires and characterized by a wide range of soil types. In Italy, it generally grows both on the Alps (generally at elevation $>500 \mathrm{~m}$ a.s.1.) and on the Apennines (elevation $>900 \mathrm{~m}$ a.s.l.).

Nine beech forests were selected all over Italy (Fig. 1). Climate characteristics at the chosen locations vary from Mediterranean (south) up to temperate (north). The average annual temperature ranges from $7.5^{\circ} \mathrm{C}$ in the north to $14.2{ }^{\circ} \mathrm{C}$ in the south; a trend of decreasing annual rainfall is observed moving from north to south, and from the highest to the lowest altitude of the sites (Tab. 1).

\section{Meteorological and ancillary data}

Meteorological information (i.e., daily minimum and maximum temperature and precipitation) for each site and for the period considered (1999-2008) was derived from the E-OBS dataset (Haylock et al. 2008). Data are freely provided at the original spatial resolution of $0.25^{\circ}$ and were then downscaled at $1-\mathrm{km}$ spatial resolution by applying locally calibrated regressions after Maselli et al. (2012).

A field survey was carried out at each site to determine the actual standing volume by directly measuring diameter at breast height (DBH) and height of trees standing within circular plots of varying radius (Tab. 2).

\section{Tree growth data}

For each site, tree growth measurements were collected and elaborated as dendrochronological series in order to retrieve reference CAI values (see Tab. 2). At each site, an area of approximately 2 ha was chosen and 15-16 living dominant and co-dominant trees were selected, with DBH ranging from 60 to $100 \mathrm{~cm}$ and height about $26 \mathrm{~m}$. Care was taken to select trees with canopies well separated from each other, in order to reduce the effect of competition on tree growth. Two cores were taken by an increment borer $0.5 \mathrm{~cm}$ in diameter from each tree, uphill at height of $1.3 \mathrm{~m}$ at an angle of $120^{\circ}$ to each other. Cores were mounted on channeled wood, seasoned in a fresh-air dry store and sanded a few months later. Tree rings were 
dated by counting them from bark to pith. Ring widths were measured to the nearest $0.01 \mathrm{~mm}$ using the LINTAB-measurement equipment, coupled to a stereomicroscope (60x magnification - Leica, Germany). The Time Series Analysis Programme (TSAP) software package (Frank Rinn, Heidelberg, Germany) was used for statistical analysis. Raw ring widths of the single series of each dated tree were cross-dated statistically by the percent agreement in the signs of the first-differences of the two time series (the Gleichlaufigkeit, GLK - Kaennel \& Schweingruber 1995). The GLK is a measure of the year-to-year agreement between the interval trends of two chronologies based upon the sign of agreement, or the sum of the equal slope intervals in per cent. With an overlap of 50 years (commonly used in tree-ring studies), GLK becomes significant $(\mathrm{p}<0.05)$ at $62 \%$ and highly significant $(\mathrm{p}<0.01)$ at $67 \%$. With an overlap of 10 years, GLK becomes significant $(\mathrm{p}<0.05)$ at $76 \%$ and highly significant $(\mathrm{p}<0.01)$ at $87 \%$ (Kaennel \& Schweingruber 1995). In this study, most time series analyzed were longer than 50 years and cross dating was considered successful if GLK was higher than $60 \%$.

The statistical significance of the GLK (GSL) was also computed. The TVBP, a Student's $t$-value modified by Baillie \& Pilcher (1973) was used for investigating the significance of the best match identified. The TVBP is commonly used as a statistical tool for comparing and cross-dating ring widths series. It determines the degree of correlation between curves and eliminates low-frequency variations in the time series, as each value is divided by the corresponding 5-year moving average.

Locally missing or discontinuous rings were identified by cross-dating the two treering cores obtained from the same tree. Standard methods (Fritts 1976) were used to build a tree averaged series and the mean chronologies of the investigated sites, using ring-width series obtained from all living trees growing at each study site.

\section{Modeling approach}

The methodology developed by our research group allows the calibration of the BIOME-BGC model for each main fores type (Chiesi et al. 2007). This is obtained by iteratively adapting the GPP estimates of the model to those of a Monteith's type, NDVIdriven parametric model, Modified C-Fix, whose accuracy has been widely tested against eddy covariance flux tower measurements (Maselli et al. 2009b, Chiesi et al. 2011a). Next, BIOME-BGC is applied for each forest site to simulate all main forest processes (Maselli et al. 2009a). In the current paper only the main steps of the methodology are summarized. Theoretical and operational details can be found in the refe-

Tab. 2 - Characteristics of the dendrochronological measurements.

\begin{tabular}{lcccc}
\hline Study site & $\begin{array}{c}\text { Length of the } \\
\text { data series }\end{array}$ & $\begin{array}{c}\text { Average tree ring } \\
\text { width }(\mathbf{m m} / \mathbf{y})\end{array}$ & $\begin{array}{c}\text { Volume } \\
\left(\mathbf{m}^{\mathbf{3}} / \mathbf{h a}\right)\end{array}$ & $\begin{array}{c}\text { CAI } \\
\left(\mathbf{m}^{\mathbf{3}} / \mathbf{h a}\right)\end{array}$ \\
\hline Dolomiti Bellunesi & $1915-2006$ & 2.24 & 380 & 5.26 \\
Pian del Cansiglio & $1814-2008$ & 2.18 & 791 & 8.22 \\
Sasso Fratino & $1827-2008$ & 2.1 & 985 & 8.94 \\
Val Cervara & $1715-2008$ & 0.92 & 364 & 1.48 \\
Monte di Mezzo & $1844-2004$ & 2.62 & 703 & 7.8 \\
Corleto & $1821-2006$ & 1.98 & 832 & 12.68 \\
Sila & $1854-2008$ & 2.14 & 775 & 10.81 \\
Aspromonte & $1824-2008$ & 1.87 & 687 & 2.07 \\
Gargano & $1827-2008$ & 1.82 & 632 & 6.23 \\
\hline
\end{tabular}

rences mentioned below.

BIOME-BGC, after a proper calibration for beech (see Chiesi et al. 2011b), is capable of estimating respiration and allocation processes of ecosystems close to equilibrium condition (Churkina et al. 2003, Waring \& Running 2007). For each study site the model can perform a self-initialization through the so-called spin-up phase, which identifies the initial state variables. In this way, the model can predict the net forest carbon fluxes depicting a quasi-equilibrium situation. More specifically, net primary production (NPP) is obtained as follows (eqn. 1):

$$
N P P=G P P-R_{g}-R_{m}
$$

where GPP, $R_{g}$ and $R_{m}$ correspond to the annual gross primary production, growth and maintenance respiration simulated by BIOME-BGC ( $\mathrm{g} \mathrm{C} \mathrm{m}^{-2}$ year $\left.^{-1}\right)$, respectively.

From NPP, CAI $\left(\mathrm{m}^{3} \mathrm{ha}^{-1}\right.$ year $\left.{ }^{-1}\right)$ can be predicted through the general formula (eqn. 2):

\section{$C A I=N P P \cdot S C A / B E F / B W D \cdot 2 \cdot 100$}

where $S C A$ corresponds to the stem carbon allocation, $B E F$ is the biomass expansion factor and $B W D$ is the basic woody density. The $S C A$ for beech is derived from the BIOME-BGC settings (White et al. 2000, Chiesi et al. 2011b), while $B E F$ and $B W D$ are 1.36 and 0.61 , respectively (Federici et al. 2008). The two scalars 2 and 100 are applied to convert CAI from carbon to dry matter and from $\mathrm{g} \mathrm{m}^{-2}$ to $\mathrm{Mg} \mathrm{ha}^{-1}$, respectively.

The effects of forest disturbances on NPP can be taken into account by applying the methodology proposed by Maselli et al. (2009a): the ratio between actual and potential tree volume is considered as an indicator of ecosystem proximity to potential biomass density, which can be used to correct the $G P P$ and respiration estimates obtained by the previous model simulations. According to this formulation, actual forest $N P P\left(N P P_{A}\right.$, $\mathrm{g} \mathrm{C} \mathrm{m}^{-2}$ year $\left.^{-1}\right)$ can be approximated as follows (eqn. 3):

$$
N P P_{A}=G P P \cdot F C_{A}-R_{g} \cdot F C_{A}-R_{m} \cdot N V_{A}
$$

where the two dimensionless terms $F C_{A}$ (actual forest cover) and $N V_{A}$ (actual normalized standing volume) are derived from the ratio between actual and potential tree volume (Maselli et al. 2009a).

The above modification works as depicted in Fig. 2a. Simulated CAI starts from 0 (no woody biomass) and increases as function of the stand volume up to a maximum value, which is slightly higher than BIOME-BGC (equilibrium) CAI due to the reduced influence of autotrophic respiration. Next, when actual biomass approaches potential biomass, respiration increases and simulated CAI tends to reach the CAI simulated by BIOME-BGC.

The strategy has been further refined to take into consideration the age-related growth decline typical of even-aged stands (Chiesi et al. 2012). This is obtained using an age-dependent relationship between stem carbon and leaf carbon, which must be calibrated for each study site and transforms $F C_{A}$ into $F C_{E A}$ (even-aged actual forest cover). Accordingly, even-aged $N P P\left(N P P_{E A}\right)$ is obtained as follows (eqn. 4):

$$
N P P_{E A}=G P P \cdot F C_{E A}-R_{g} \cdot F C_{E A}-R_{m} \cdot N V_{A}
$$

As fully explained by Chiesi et al. (2012), applying the above equation leads to modify the relationship between photosynthesis and autotrophic respiration in an age-dependent way. Consequently, for a certain woody biomass, tree aging has an inhibiting effect on the predicted CAI. This is schematized in Fig. 2b, where the ratio between aging CAI and BIOME-BGC (equilibrium) CAI is much higher than 1 for young stands and tends to decrease and level off for older stands.

\section{Data processing}

\section{Elaboration of dendrochronological data series}

Dendrochronological measurements (i.e., annual tree ring widths) collected in each forest site were elaborated to retrieve forest volume variations during the stand develop- 

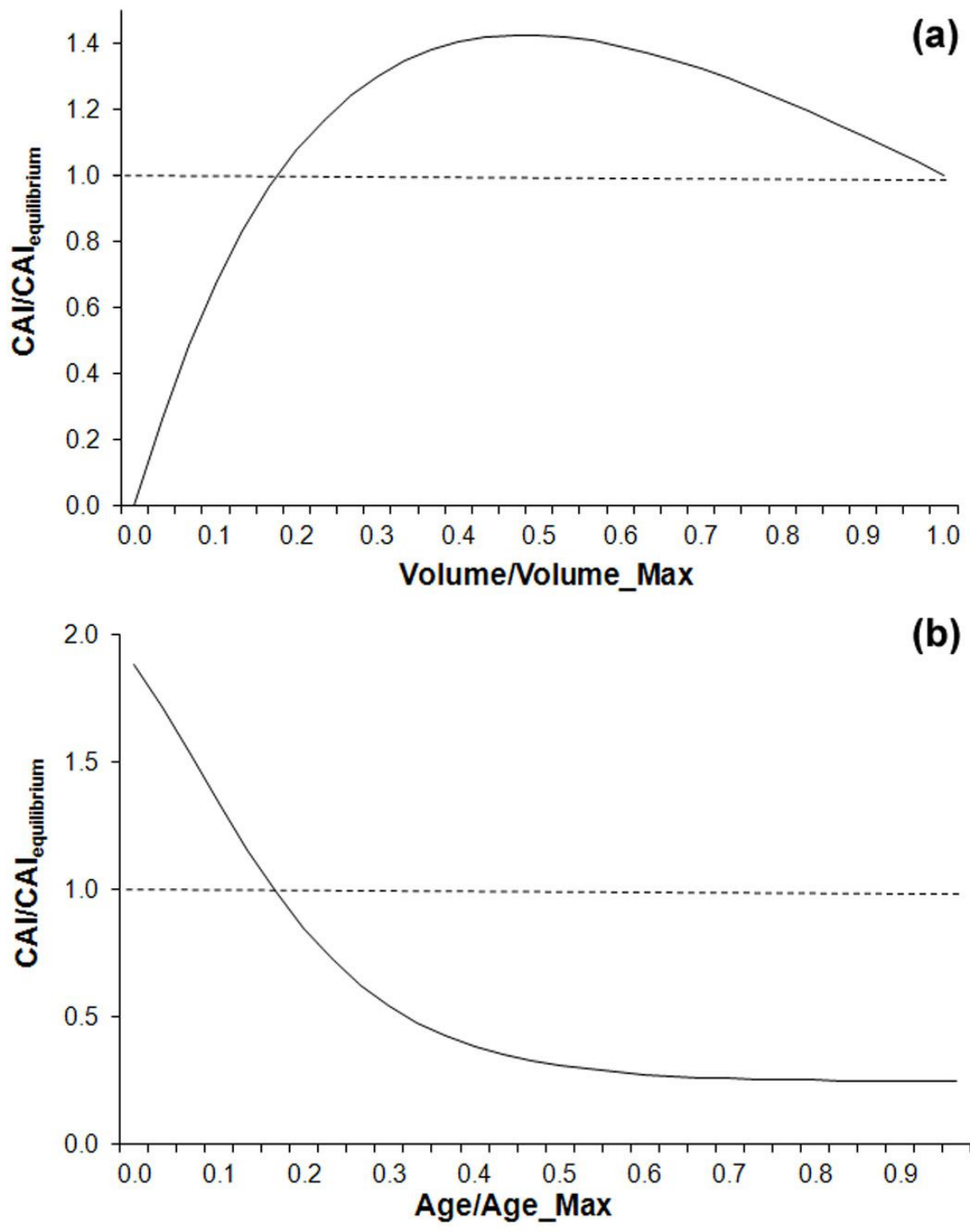

Fig. 2 - Effects of biomass (a) and age (b) variations on simulated CAIs. Both curves are relative to BIOME-BGC CAI modeling at equilibrium conditions and are derived from Maselli et al. (2009a) and Chiesi et al. (2012), respectively; in the latter case a stem volume lower than the potential maximum is considered (see text for details).

ment since the planting date. To this aim, the DBH was first reconstructed by summing up the tree ring widths. A cubic function was then applied to retrieve the stem volume corresponding to each diameter measurement (Tabacchi et al. 2011). This volume was then normalized against the actual forest volume measured in the field (see Tab. 1). The annual CAIs were finally calculated as the difference between the stem volumes of two successive years. To validate the simulation methods, reference CAI values were obtained for each of the nine sites considered by averaging the annual CAI over the last five years available.

\section{Simulation of forest CAIS}

First, the input layers required to apply the BIOME-BGC model were prepared. The 1- $\mathrm{km}$ spatial resolution minimum and maximum temperature and precipitation data for the years 1999-2008 (see above) were further elaborated to obtain solar radiation by using the MT-CLIM algorithm (Thornton et al. 2000)

The modeling strategy was first applied to simulate ecosystems in equilibrium conditions. In particular, BIOME-BGC was applied using the ecophysiological parameters reported by Chiesi et al. (2011b), and NPP and CAI were predicted using eqn. 1 and 2 .

Next, the effects of biomass removal were obtained by applying eqn. 3. In particular, both $\mathrm{NV}_{\mathrm{A}}$ and $\mathrm{FC}_{\mathrm{A}}$ were calculated using the measured stem volume for each stand (see Tab. 2). $\mathrm{NV}_{\mathrm{A}}$ was the ratio between actual and potential stem volume, while $\mathrm{FC}_{\mathrm{A}}$ was computed using the maximum stand LAI (see Maselli et al. 2009a for more details).

Finally, the effects of stand aging were simulated using both a unique modeling of the leaf carbon/stem carbon temporal variability and site specific modeling of the same variability using eqn. 4 (see Chiesi et al. 2012 for details). In the first case, a general growth curve was calibrated by statistically reproducing the average of all available reference CAIs derived from dendrochronological measurements with the exclusion of the last 5 years; this allowed an approximate independence of the calibration and validation phases. As for the second case, the same calibration process was repeated by fitting a specific growth curve for each study site.

In all cases, the obtained CAI estimates were averaged over the 5 study years and compared to the reference CAI measurements using the correlation coefficient (r), the root mean square error (RMSE) and the mean bias error (MBE) as accuracy statistics.

\section{Results}

The study sites are located in mountain areas at elevations ranging between 775 and $1780 \mathrm{~m}$ a.s.1. As a consequence of different latitudes and elevations, the annual average air temperature and the total annual precipitation derived from the downscaled E-OBS dataset are highly variable: air temperature ranges between $7.5{ }^{\circ} \mathrm{C}$ and $14.2{ }^{\circ} \mathrm{C}$, while precipitation ranges between $510 \mathrm{~mm} \mathrm{y}^{-1}$ and $1710 \mathrm{~mm} \mathrm{y}^{-1}$ - Tab. 1).

The beech forests analyzed show different structural characteristics, which are related to the different age of trees. Tab. 2 reports the average tree ring widths, which vary between 0.92 and $2.62 \mathrm{~mm} \mathrm{y}^{-1}$, where the oldest stand shows the lowest tree ring width (Val Cervara). The same general trend is observed for CAI measurements, which range between 1.5 and $12.7 \mathrm{~m}^{3} \mathrm{ha}^{-1}$, depending on different environmental conditions, structures and development phases of the nine study sites considered.

Results shown in Fig. 3 are obtained using the BIOME-BGC GPP, respirations and allocations for forests in quasi-equilibrium with site-specific climatic and soil conditions. The correlation between measured and predicted CAIs is moderate $(r=0.516)$, and the range of variation was strongly underestimated. CAI is particularly overestimated for Val Cervara (7.79 vs. $\left.1.41 \mathrm{~m}^{3} \mathrm{ha}^{-1}\right)$, which is the less dense and oldest stand (see Tab. 2). This leads to a relatively high overall RMSE $\left(2.57 \mathrm{~m}^{3} \mathrm{ha}^{-1}\right)$, indicating that the exclusion of actual forest conditions (in terms of existing biomass and development phase) implies a flawed simulation of CAI variations.

A slight improvement is obtained including the information on the existing stem volume into the model. The comparison between measured and estimated CAI is shown in 


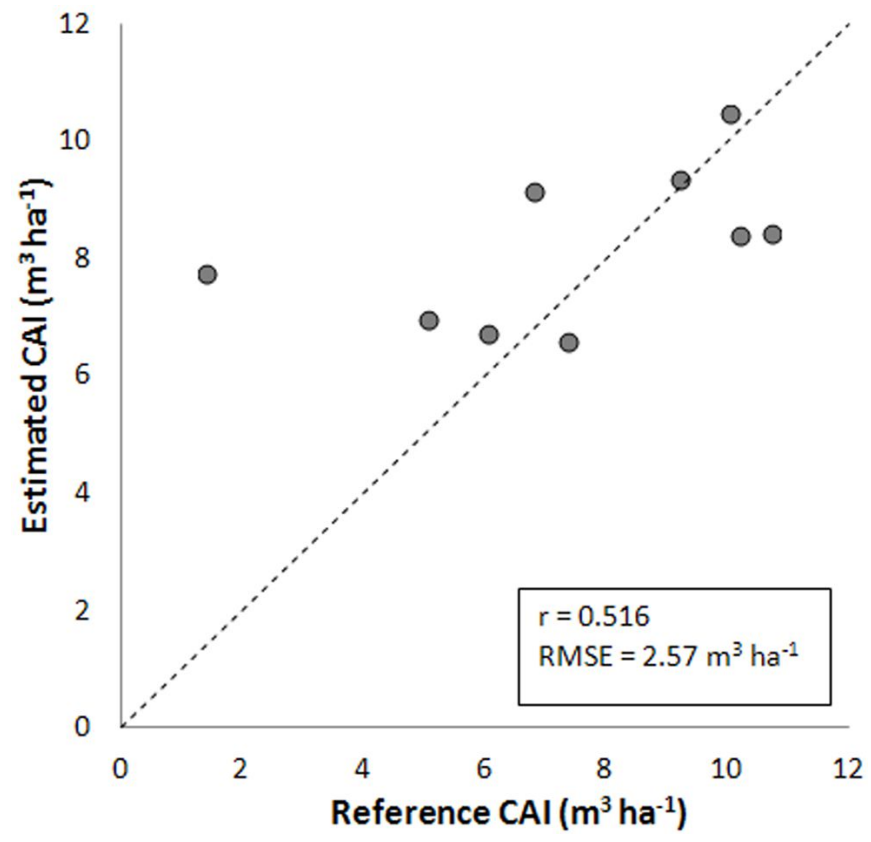

Fig. 3 - Comparison between CAI measured and estimated using BIOME-BGC simulation of equilibrium (quasi-climax) forest conditions (see text for details).

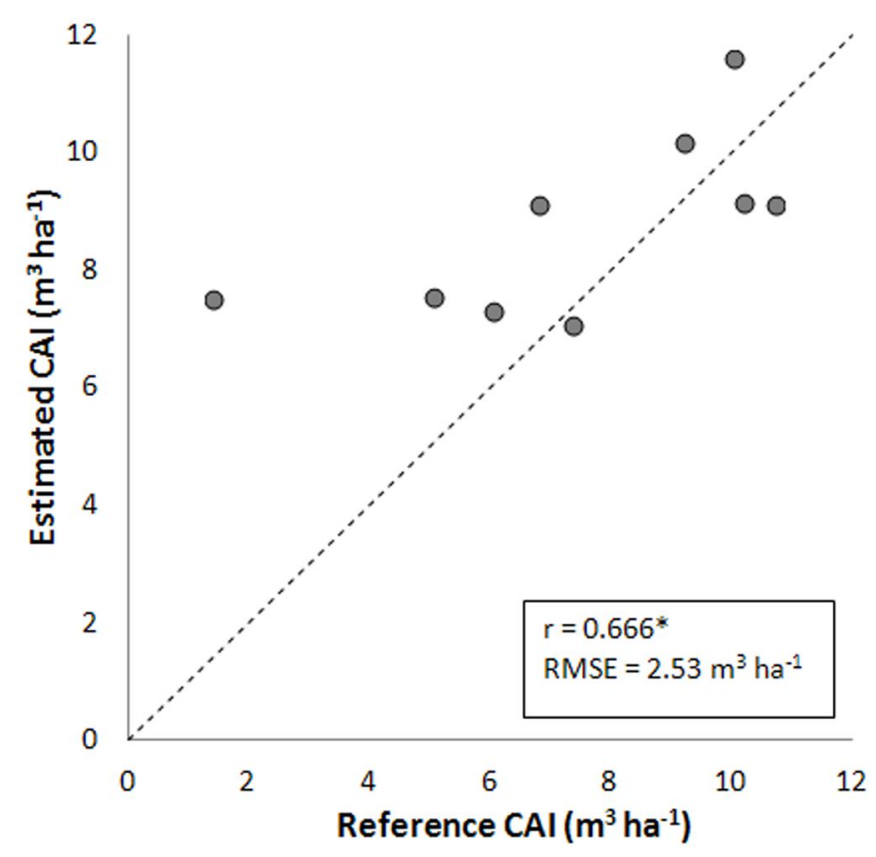

Fig. 4 - Comparison between CAI measured and estimated by including volume information about each site (see text for details). (*): significant correlation, $\mathrm{P}<0.05$.
Fig. 4. CAI overestimation for Val Cervara reported in Fig. 3 is marginally reduced, and the global estimation accuracy is slightly increased $\left(r=0.666, \mathrm{RMSE}=2.53 \mathrm{~m}^{3} \mathrm{ha}^{-1}\right)$.

Further improvements in predictions are obtained when the stand development stage is included in the model, based on the available dendrochronological measurements

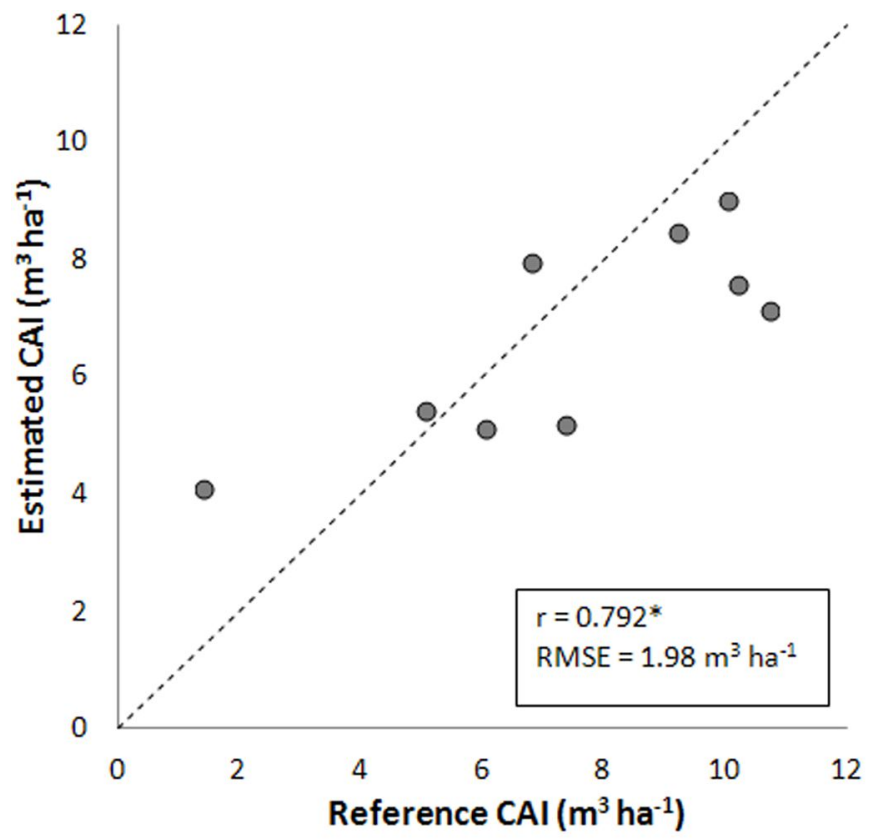

Fig. 5 - Comparison between CAI measured and estimated by applying a generic age-dependent growth curve (see text for details). (*): significant correlation, $\mathrm{P}<0.05$. and the method reported by Chiesi et al. reduces the former overestimation for Val (2012). More specifically, the use of a generic growth curve for all beech forests yields the results shown in Fig. 5. The correlation coefficient is notably increased $(r=0.792)$, and the error markedly reduced $(\mathrm{RMSE}=$ $1.98 \mathrm{~m}^{3} \mathrm{ha}^{-1}$. Indeed, the inclusion of generic information on beech stand development Cervara, though a slight underestimation at high CAI values is observed.

An additional improvement in simulations is obtained when locally derived growth curves are calibrated to better characterize the specific stand development phase of each site (Fig. 6). In this case, reference CAIs are

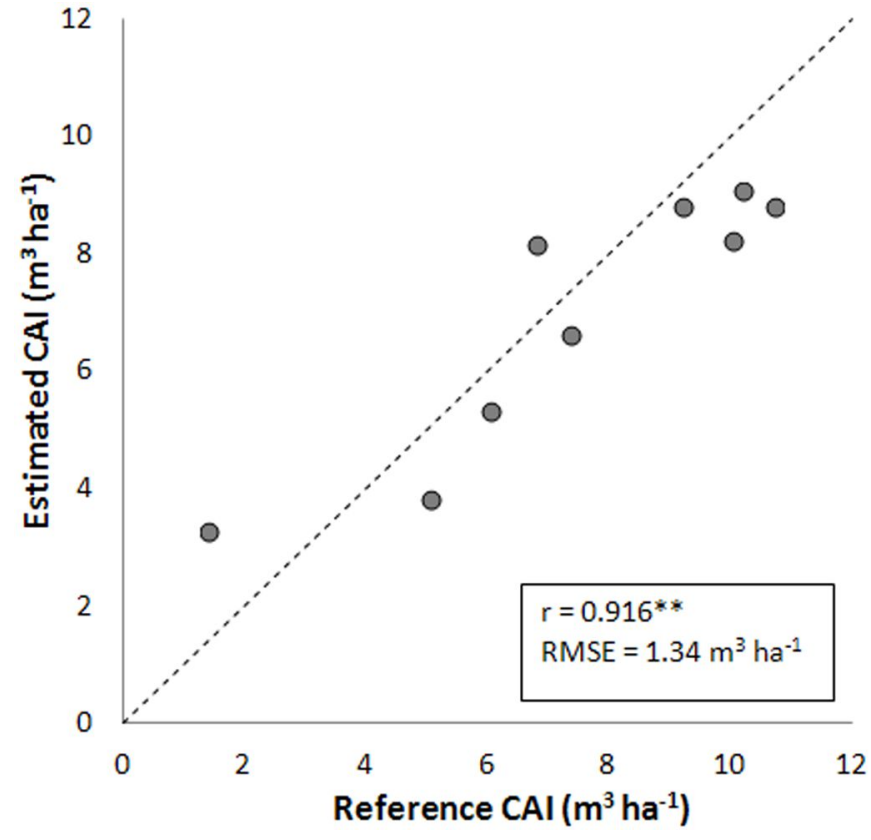

Fig. 6 - Comparison between CAI measured and estimated by applying an age-dependent growth curve calibrated for each single stand (see text for details). (**): highly significant correlation, $\mathrm{P}<$ 0.01 . 
fairly well simulated for all study sites considered, with a high correlation coefficient $(r=0.916)$, and a RMSE strongly reduced $\left(1.34 \mathrm{~m}^{3} \mathrm{ha}^{-1}\right)$.

\section{Discussion and conclusions}

Several recent papers have demonstrated that a modeling strategy based on the use of a calibrated bio-geochemical model is capable of predicting gross and net forest carbon fluxes within Mediterranean forests (e.g., Mu et al. 2007, Turner et al. 2006, Maselli et al. 2009a, 2010, Chiesi et al 2011a, 2012). Modeling can be applied a different levels of complexity, depending on the existing knowledge of the forest ecosystems considered. This is expected to affect the accuracy of the proposed strategy in a way that is important to be assessed in sight of operational monitoring applications.

The current study investigates on this issue using ground and remote sensing information collected over nine beech sites in Italy. The availability of dendrochronological sequences of tree ring-widths has allowed a thorough characterization of the past and present growth status of the considered forest stands, providing essential information for both calibrating and validating the modeling simulations.

In general, the accuracy of the modeling strategy is affected by the uncertainty of the input data used. While a full assessment of this topic has been performed in previous papers (e.g., Chiesi et al. 2011a, Maselli et al 2012), the critical nature of the extended meteorological model drivers must be highlighted. This is particularly the case for the daily rainfall estimates, whose accuracy is relatively low due to a number of problems (Maselli et al. 2012).

The proposed use of BIOME-BGC allows to reproduce the carbon accumulated by forests which are in quasi-equilibrium with local climatic and soil conditions. This means that the annual net fluxes are close to zero because of the nearly equivalence of forest production and respiration; additionally, such models simulate forests composed by trees in different growing phases (Running \& Hunt 1993, Maselli et al 2009a). The model can be applied in a relatively simple way, requiring only information on forest types and eco-climatic conditions, which is now available for the European continent from several sources (e.g., Pekkarinen et al. 2009, Haylock et al. 2008). On the other hand, the exclusion of biomass removal and stand aging from the model usually leads to underestimate the range of CAI variations (Maselli et al. 2009a, Chiesi et al. 2012). As reported in Fig. 2, the two factors above can increase or decrease the simulated CAI depending on the ecosystem closeness to potential, quasiequilibrium condition.
The additional inclusion of a proxy of the ecosystem distance from equilibrium (i.e., the stand volume information) accounts for the effect of biomass removal and generally improves the simulation results (Maselli et al. 2009a). However, the forests examined in this study are nearly fully stocked and old growth, which reduces the effect of biomass removal and enhances that of age-related decline in forest production (Gower et al. 1996, Chiesi et al. 2012). The latter factor is not accounted for by this modeling step, which therefore improves the predictions only marginally. A different situation would occur in uneven-aged stands having biomass much lower than potential; in such a case, the inclusion of biomass removal into the model would be decisive for CAI simulation (Maselli et al. 2010). From an operational point of view, including the information on the existing biomass makes the application of the simulation method more complex, since spatially distributed estimates of stem volume are usually difficult to retrieve. Efforts in this direction, however, have been recently performed. For example, Gallaun et al. (2008) produced and disseminated a $1-\mathrm{km}$ stem volume map covering all European forest areas. Maselli et al. (2014) performed a similar effort for the Italian territory by combining ground stem volume measurements with optical and LiDAR satellite data.

According to the previous considerations, an additional methodological improvement is provided by modeling the effects of stand aging. In fact, tree aging leads to decreased accumulation rates due to the well-known phenomenon of age-related decline in forest production (e.g., Gower et al. 1996, Berger et al. 2004). The causes of this phenomenon are numerous and mainly related to environmental and external factors (e.g., silvicultural practices, forest fires, etc. - Zhou et al. 2002). The availability of dendrochronological measurements enables to characterize the whole stand development of the beech forests and to reconstruct the temporal variations of CAI with stand age. This was obtained by defining an age-dependent relationship between leaf carbon and stem carbon accounting for the temporally varying ratios between forest production and respiration related to changes in canopy density, tree competition and allocation patterns.

In the current study this operation has been carried out in two steps: first, applying a general relationship between leaf carbon and stem carbon; and, second, using a site-specific relationship. This has improved the accuracy of the estimates especially in the latter case ( $r=0.916$ - see Fig. 6). In addition to a few dendrochronological tree ring-width sequences, the application of the first methodological step would require spatially distributed estimates of stand age. Efforts in this direction have been recently performed:
Vilén et al. (2012), for example, produced and disseminated a $1-\mathrm{km}$ map of forest age covering all Europe.

For relatively small areas an alternative could be provided by tree height estimates obtained from LiDAR data, which can be used as a proxy of tree age (Maselli et al. 2013), though old small individuals and, vice-versa, trees with huge biomass accumulated in few decades, can be found in forest ecosystems (Marziliano et al. 2012). Finally, as regards the last step, its application on regional to national scales is virtually unfeasible, since the dendrochronological measurements needed to characterize specific site history can be obtained only for small areas.

In summary, the current study has shown that the inclusion of progressively increasing information levels on forest conditions within the model allows to obtain reliable predictions of stand CAI over large areas. However, the complete simulation of the effects of human induced factors requires a full characterization of specific site history, which is practically unfeasible over large areas. Consequently, a certain approximation must be accepted for operational applications, depending on the spatio-temporal scales considered and on the nature and accuracy of the available datasets.

\section{Acknowledgments}

The Italian Ministry of Education, University and Research funded this study under the FIRB2008 program, project "Modelling the carbon sink in Italian forest ecosystems using ancillary data, remote sensing data and productivity models" C_FORSAT (code: RBFR08LM04, national coordinator: G. Chirici).

The authors acknowledge the E-OBS dataset from the EU-FP6 project ENSEMBLES (http://ensembles-eu.metoffice.com) and the data providers in the ECA\&D project (http://eca.knmi.nl). The authors also wish to thank Dr. M. Pasqui for pre-processing the data from the E-OBS dataset, Dr. L. Fibbi, Dr. M. Moriondo and Prof. M. Bindi for assisting in the calibration and application of BIOME-BGC.

The authors wish to thank two anonymous reviewers for their precious comments on the first draft of the manuscript.

\section{References}

Allen CD, Macalady AK, Chenchouni H, Bachelet $\mathrm{D}$, McDowell N, Vennetier M, Kitzberger $\mathrm{T}$, Rigling A, Breshears DD, Hogg EH, Gonzalez P, Fensham R, Zhang Z, Castro J, Demidova N, Lim J-H, Allard G, Running SW, Semerci A, Cobb N (2010). A global overview of drought and heat-induced tree mortality reveals emerging climate change risks for forests. Forest Ecology and Management 259: 660-684. - doi: 10.1016/ j.foreco.2009.09.001 
Assmann E (1970). The principles of forest yield study. Pergamon Press, Oxford, UK.

Baillie MGL, Pilcher JR (1973). A simple crossdating program for tree-ring research. Tree-Ring Bulletin 33: 7-14.

Berger U, Hildenbrandt H, Grimm V (2004). Agerelated decline in forest production: modelling the effects of growth limitation, neighbourhood competition and self-thinning. Journal of Ecology 92: 846-853. - doi: 10.1111/j.0022-0477. 2004.00911.x

Chiesi M, Maselli F, Moriondo M, Fibbi L, Bindi M, Running S (2007). Application of BIOME-BGC to simulate Mediterranean forest processes. Ecological Modelling 206: 179-190. doi: 10.1016/j.ecolmodel.2007.03.032

Chiesi M, Fibbi L, Genesio L, Gioli B, Magno R, Maselli F, Moriondo M, Vaccari FP (2011a). Integration of ground and satellite data to model Mediterranean forest processes. International Journal of Applied Earth Observation and Geoinformation 13: 504-515. - doi: 10.1016/j.jag. 2010.10.006

Chiesi M, Maselli F, Chirici G, Barbati A, Corona $\mathrm{P}$ (2011b). Use of BIOME-BGC to simulate Mediterranean forest carbon stocks. iForest 4: 121127. - doi: 10.3832/ifor0561-004

Chiesi M, Cherubini P, Maselli F (2012). Adaptation of a modelling strategy to predict the NPP of even-aged forest stands. European Journal of Forest Research 131: 1175-1184. - doi: 10.1007/ s10342-011-0588-z

Churkina G, Tenhunen J, Thornton P, Falge EM, Elbers JA, Erhard M, Grunwald T, Kowalski AS, Rannik U, Sprinz D (2003). Analyzing the ecosystem carbon dynamics of four European coniferous forests using a biogeochemistry model. Ecosystems 6: 168-184. - doi: 10.1007/s10021002-0197-2

Coops NC, Waring RH, Landsberg JJ (1998). Assessing forest productivity in Australia and New Zealand using a physiologically-based model driven with averaged monthly weather data and satellite-derived estimates of canopy photosynthetic capacity. Forest Ecology and Management 104: 113-127. - doi: 10.1016/S0378-1127(97) 00248-X

Corona P (2010). Integration of forest inventory and mapping to support forest management iForest 3: 59-64. - doi: 10.3832/ifor0531-003

FAO (2010). Global forest resources assessment. Forestry Paper no. 163, Food and Agriculture Organization of the United Nations, Rome, Italy, pp. 340. - [online] URL: http://www.fao.org/fore stry/fra/fra2010/en/

Federici S, Vitullo M, Tulipano S, De Lauretis, R Seufert G (2008). An approach to estimate carbon stocks change in forest carbon pools under the UNFCCC: the Italian case. iForest 1: 86-95. doi: 10.3832/ifor0457-0010086

Fritts HC (1976). Tree rings and climate. Academic Press, London, UK.

Gallaun H, Zanchi G, Nabuurs G-J, Hengeveld G, Schardt M, Verkerk PJ (2008). EU-wide maps of growing stock and above-ground biomass in forests based on remote sensing and field meas- urements. Forest Ecology and Management 260: 252-261. - doi: 10.1016/j.foreco.2009.10.011

Gower ST, McMurtrie RE, Murty D (1996). Aboveground net primary production decline with stand age: potential causes. Trends in Ecology and Evolution 11 (9): 378-382. - doi: 10.1016/0169-5347(96)10042-2

Haylock MR, Hofstra N, Klein Tank AMG, Klok EJ, Jones PD, New M (2008). A European daily high-resolution gridded dataset of surface temperature and precipitation. Journal of Geophysical Research (Atmospheres) 113: D20119. - doi: 10.1029/2008JD10201

Kaennel M, Schweingruber FH (1995). Multilingual glossary of dendrochronology. Terms and definitions in English, German, French, Spanish, Italian, Portuguese, and Russian. Swiss Federal Institute for Forest, Snow and Landscape Research, Haupt, Bern, Switzerland, pp. 467.

Marziliano P, Menguzzato G, Scuderi A, Corona P (2012). Simplified methods to inventory the current annual increment of forest standing volume. iForest 5: 276-282. - doi: 10.3832/ ifor0635-005

Maselli F, Chiesi M, Moriondo M, Fibbi L, Bindi M, Running SW (2009a). Modelling the forest carbon budget of a Mediterranean region through the integration of ground and satellite data. Ecological Modelling 220: 330-342. - doi: 10.1016/ j.ecolmodel.2008.10.002

Maselli F, Papale D, Puletti N, Chirici G, Corona $P$ (2009b). Combining remote sensing and ancillary data to monitor the gross productivity of water-limited forest ecosystems. Remote Sensing of Environment 113: 657-667. - doi: 10.1016/j.rse. 2008.11.008

Maselli F, Chiesi M, Barbati A, Corona P (2010). Assessment of forest net primary production through the elaboration of multisource ground and remote sensing data. Journal of Environmental Monitoring 12: 1082-1091. - doi: 10. 1039/b924629k

Maselli F, Pasqui M, Chirici G, Chiesi M, Fibbi L, Salvati R, Corona P (2012). Evaluation of a 1$\mathrm{km}$ daily meteorological dataset for modelling vegetation production in Italy. Climate Research 54: 271-285. - doi: 10.3354/cr01121

Maselli F, Mari R, Chiesi M (2013). Use of LiDAR data to simulate forest net primary production. International Journal of Remote Sensing 34: 2487-2501. - doi: 10.1080/01431161.2012. 7450 19

Maselli F, Chiesi M, Mura M, Marchetti M, Corona P, Chirici G (2014). Combination of optical and LiDAR satellite imagery with forest inventory data to improve wall-to-wall assessment of growing stock in Italy. International Journal of Applied Earth Observation and Geoinformation 26: 377-386. - doi: 10.1016/j.jag.2013.09.001

Mu Q, Zhao M, Heinsch FA, Liu M, Tian H, Running SW (2007). Evaluating water stress controls on primary production in biogeochemical and remote sensing based models. Journal of Geophysical Research 112: G01012. - doi: 10.1029/20 06JG000179

Pekkarinen A, Reithmaier L, Strobl P (2009). Pan-
European forest/non-forest mapping with Landsat ETM+ and CORINE Land Cover 2000 data. ISPRS Journal of Photogrammetry and Remote Sensing 64: 171-183. - doi: 10.1016/j.isprsjprs. 2008.09.004

Powell SL, Cohen WB, Healey SP, Kennedy RE, Moisen GG, Pierce KB, Ohmann JL (2010). Quantification of live aboveground forest biomass dynamics with Landsat time-series and field inventory data: a comparison of empirical modeling approaches. Remote Sensing of Environment 114: 1053-1068. - doi: 10.1016/j.rse. 2009.12.018

Running SW, Hunt ER (1993). Generalization of a forest ecosystem process model for other biomes, BIOME-BGC, and an application for global-scale models. In: "Scaling physiological processes: leaf to globe" (Ehleringer JR, Field CB eds). Academic Press, San Diego, USA, pp. 141158.

Smith FW, Long JN (2001). Age-related decline in forest growth: an emergent property. Forest Ecology and Management 144: 175-181. - doi: 10.1016/S0378-1127(00)00369-8

Tabacchi G, Di Cosmo L, Gasparini P, Morelli S (2011). Stima del volume e della fitomassa delle principali specie forestali italiane. Equazioni di previsione, tavole del volume e tavole della fitomassa arborea epigea. Consiglio per la Ricerca e la sperimentazione in Agricoltura, Trento, Italy, pp. 412. [in Italian]

Thornton PE, Hasenauer H, White MA (2000). Simultaneous estimation of daily solar radiation and humidity from observed temperature and precipitation: an application over complex terrain in Austria. Agricultural and Forest Meteorology 104: 255-271. - doi: 10.1016/S0168-1923 (00)00170-2

Tupek B, Zanchi G, Verkerk PJ, Churkina G, Viovy N, Hughes JK, Lindner M (2010). A comparison of alternative modelling approaches to evaluate the European forest carbon fluxes. Forest Ecology and Management 260: 241-251. doi: 10.1016/j.foreco.2010.01.045

Turner DP, Ritts WD, Cohen WB, Gower ST, Running SW, Zhao M, Costa MH, Kirschbaum A, Ham J, Saleska S, Ahl DE (2006). Evaluation of MODIS NPP and GPP products across multiple biomes. Remote Sensing of Environment 102: 282-292. - doi: 10.1016/j.rse.2006.02.017

Vilén T, Gunia K, Verkerk PJ, Seidl R, Schelhaas M-J, Lindner M, Bellassen V (2012). Reconstructed forest age structure in Europe 19502010. Forest Ecology and Management 286: 203-218. - doi: 10.1016/j.foreco.2012.08.048

Wang S, Zhou L, Chen J, Ju W, Feng X, Wu W (2011). Relationships between net primary productivity and stand age for several forest types and their influence on China's carbon balance. Journal of Environmental Management 92: 1651-1662. - doi: 10.1016/j.jenvman.2011.01.0 24

Waring HR, Running SW (2007). Forest ecosystems. Analysis at multiples scales $\left(3^{\text {rd }}\right.$ edn). Academic Press, San Diego, CA, USA.

White MA, Thornton PE, Running SW, Nemani 
RR (2000). Parameterisation and sensitivity analysis of the BIOME-BGC terrestrial ecosystem model: net primary production controls. Earth Interactions 4: 1-85. - doi: 10.1175/1087-3562
(2000)004<0003:PASAOT>2.0.CO;2

Zhou G, Wang Y, Jiang Y, Yang Z (2002). Estimating biomass and net primary production from forest inventory data: a case study of China's
Larix forests. Forest Ecology and Management 169: 149-157. - doi: 10.1016/S0378-1127(02) 00305-5 